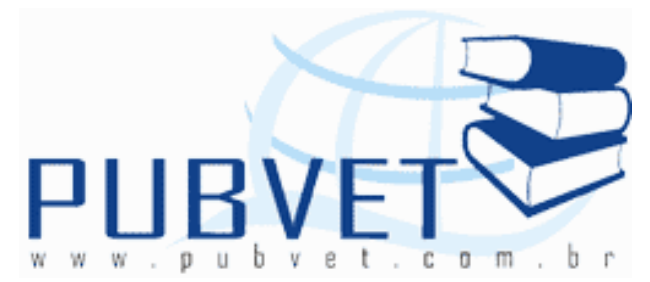

PUBVET, Publicações em Medicina Veterinária e Zootecnia.

\title{
Mycoplasma haemofelis em gato - relato de caso
}

\author{
Elissandra da Silveira ${ }^{1}$, Mariana Caetano Pimentel ${ }^{2}$, Sandra Márcia Tietz \\ Marques $^{3 *}$
}

1. Graduação em Medicina Veterinária, Faculdade de Veterinária, Universidade Federal do Rio Grande do Sul.

2. Médica Veterinária, Consultório Veterinário Bichos \& Petiscos, Rio de Janeiro.

3. Médica Veterinária, PhD., Departamento de Patologia Clínica Veterinária, Faculdade de Veterinária, Universidade Federal do Rio Grande do Sul.

* Autor para correspondência: Faculdade de Veterinária, UFRGS, Av. Bento Gonçalves, 9090. Bairro Agronomia, Porto Alegre, RS. CEP:91540-000. E-mail: smtmuni@hotmail.com

\section{Resumo}

Mycoplasma haemofelis é uma bactéria pleomórfica que parasita as hemácias de várias espécies domésticas e de potencial zoonótico. O presente relato apresenta o caso de um felino, fêmea, não castrada, dois anos de idade, da raça persa com histórico de anorexia, leve desidratação, prostração, escore corporal entre 1 e 2, letargia, linfonodos mandibulares e poplíteos aumentados de tamanho, mucosas levemente hipocoradas, TR $40.3^{\circ} \mathrm{C}$, urina concentrada e esplenomegalia moderada. O resultado da avaliação hematológica, bioquímica e o exame de PCR apontaram para o caso de micoplasmose felina. A 
SILVEIRA, E., PIMENTEL, M.C. e MARQUES, S.M.T. Mycoplasma haemofelis em gato, relato de caso. PUBVET, Londrina, V. 8, N. 13, Ed. 262, Art. 1741, Julho, 2014.

terapêutica instituída com doxiciclina e dexametasona resultou na cura clínica do paciente.

Palavras-chave: Micoplasma hemotrópico, anemia infecciosa felina, PCR, perfil hematológico.

\title{
Mycoplasma haemofelis in a cat - a case report
}

\begin{abstract}
Mycoplasma haemofelis is a potentially zoonotic pleomorphic bacterium that infects the erythrocytes of several domestic species. The present report describes the case of a female, 2-year-old, unspayed Persian cat with a history of anorexia, mild dehydration, prostration, body condition score between 1 and 2, lethargy, enlarged mandibular and popliteal lymph nodes, slightly pale mucosae, rectal temperature of $40.3^{\circ} \mathrm{C}$, concentrated urine, and moderate splenomegaly. The biochemical, blood test, and PCR results indicated infection by Mycoplasma haemofelis. The patient was cured with the administration of doxycycline and dexamethasone.
\end{abstract}

Keywords: Hemotropic mycoplasma, feline infectious anemia, PCR, hematological profile.

\section{INTRODUÇÃO}

Mycoplasma haemofelis é uma bactéria pleomórfica que parasita hemácias de várias espécies domésticas, acarretando anemia hemolítica imunomediada, muitas vezes fatal. Com o surgimento da PCR, por amplificação do DNA Haemobartonella felis foi renomeada Mycoplasma haemofelis (NEIMARK et al., 2001). É transmitida pelo sangue infectado, através da picada de carrapatos e pulgas, por mordida, pela exposição iatrogênica, pelas gatas aos seus filhotes, no útero, nascimento ou aleitamento (THRALL et al., 2007). A infecção é fortemente associada com gatos machos sem pedigree e de acesso à rua (SYKES et al., 2008). 
SILVEIRA, E., PIMENTEL, M.C. e MARQUES, S.M.T. Mycoplasma haemofelis em gato, relato de caso. PUBVET, Londrina, V. 8, N. 13, Ed. 262, Art. 1741, Julho, 2014.

A doença apresenta duas fases: a aguda, caracterizada por esplenomegalia e a fase crônica com anorexia, febre, hematúria, anemia e hemorragia, podendo ter status subclínico. A parasitemia é intermitente e os micoplasmas nem sempre são identificados no esfregaço sanguíneo. O diagnóstico é feito através do histórico, sinais clínicos apresentados e do exame parasitológico através de ensaios baseados na PCR (BRAGA et al., 2012).

Estudos recentes no Brasil usando técnicas moleculares detectaram micoplasmas hemotrópicos em diferentes mamíferos, além de gatos domésticos, como gatos selvagens livres ou cativos, cães e canídeos de zoológicos, em São Paulo, Mato Grosso e Distrito Federal e em criações comerciais de suínos (BIONDO et al., 2009; ANDRÉ et al., 2011).

O presente trabalho relata um caso de felino doméstico diagnosticado com Mycoplasma haemofelis, abordando os aspectos clínico, diagnóstico e terapêutico.

\section{RELATO DE CASO}

Uma gata domiciliada, da raça Persa, não castrada, dois anos, foi atendida no Consultório Veterinário LunaVet, em Nova Friburgo/RJ, com histórico de anorexia há 3 dias, sem histórico de vômito e diarreia. Vinte dias precedentes, a fêmea pariu, na época sendo diagnosticada com Vírus da Leucemia Felina (FeLV). Durante o exame físico foi constatada leve desidratação, prostração, escore corporal entre 1 e 2 (escala de 1 a 5), letargia, linfonodos mandibulares e poplíteos aumentados de tamanho, mucosas levemente hipocoradas, temperatura retal de $40.3^{\circ} \mathrm{C}$, urina concentrada e esplenomegalia moderada. Os demais parâmetros avaliados encontravam-se dentro da normalidade para a espécie. Na primeira consulta, foram solicitados os exames laboratoriais de perfil bioquímico, hematológico e diagnóstico molecular por PCR para Mycoplasma haemofelis. Não foi solicitado exame parasitológico por esfregaço sanguíneo. 
SILVEIRA, E., PIMENTEL, M.C. e MARQUES, S.M.T. Mycoplasma haemofelis em gato, relato de caso. PUBVET, Londrina, V. 8, N. 13, Ed. 262, Art. 1741, Julho, 2014.

Os exames laboratoriais revelaram hemoglobina, hematócrito, volume corpuscular médio e hemoglobina corpuscular média, leucócitos, eosinófilos e plaquetas diminuídas, caracterizando uma anemia regenerativa, trombocitopenia, discreta neutrofilia e diminuição do valor sérico da creatinina. Pela PCR, a gata foi diagnosticada com Mycoplasma haemofelis.

\section{DISCUSSÃO}

A anemia associada com a infecção por M. haemofelis é tipicamente regenerativa, mostrando anisocitose e policromasia, com um aumento absoluto do número de reticulócitos. O animal permaneceu internado. A sintomatologia e os resultados laboratoriais corroboram com dados da literatura (NORSWORTHY, 2004; THRALL et al., 2007; SYKES et al., 2008; SYKES, 2010).

Durante 15 dias a gata permaneceu em acompanhamento veterinário, mantida em fluidoterapia endovenosa com Ringer Lactato, suplementada de três ampolas de glicose e uma ampola de complexo B; dipirona, 25mg/kg IM, BID, durante 3 dias; ranitidina 2mg/kg IV, BID durante 15 dias; Glicopan dose total de $0,5 \mathrm{~mL}$ VO, BID, durante 2 dias; ondasetrona $0,5 \mathrm{mg} / \mathrm{Kg}$ IV, BID, durante 2 dias e alimentação com ração terapêutica a/d Hills $\circledast$. Com diagnóstico de Mycoplasma haemofelis foi instituída terapêutica antimicrobiana com doxiciclina $5 \mathrm{mg} / \mathrm{kg}$ VO, BID, durante 15 dias e dexametasona 0,5mg/kg VO, SID. Glicopan foi substituído por Ferrofood, mantendo-a na dose total de $0,3 \mathrm{~mL}$ VO, SID, por 13 dias.

Para o tratamento utilizam-se antibióticos, sendo descrito na literatura preferencialmente $o$ uso de doxiciclina, tetraciclina, oxitetraciclina e enrofloxacina, corticóides e fluidoterapia. A transfusão de sangue é realizada quando houver anemia grave. A terapia com corticóide suprime a hemólise imunomediada e a doxiciclina é efetiva contra o parasito (THRALL et al., 2007). 
SILVEIRA, E., PIMENTEL, M.C. e MARQUES, S.M.T. Mycoplasma haemofelis em gato, relato de caso. PUBVET, Londrina, V. 8, N. 13, Ed. 262, Art. 1741, Julho, 2014.

Durante o período de acompanhamento veterinário e quinze dias após o início do tratamento foi realizado novo hemograma, que revelou hemácia, hemoglobina e hematócrito diminuídos, neutrofilia e trombocitopenia. Um mês após o início do tratamento foi solicitada outra avaliação sanguínea, que mostrou eritrograma e leucograma dentro da normalidade para a espécie, com exceção das plaquetas que se mantiveram em número reduzido durante todo o processo nosológico da paciente. Para diagnóstico, o esfregaço sanguíneo é uma técnica pouco sensível, por isso é de grande importância que o diagnóstico seja realizado através da utilização de provas moleculares como a PCR que detecta parasitos mesmo não estando em parasitemia persistente.

O prognóstico para Mycoplasma haemofelis geralmente é favorável, desde que a crise anêmica seja revertida. Porém, alguns gatos sofrem anemias fatais em decorrência de baixos volumes globulares. Recomenda-se que gatos com diagnóstico positivo para micoplasmose não devem ser doadores de sangue, pois se tornam portadores crônicos (NORSWORTHY, 2004).

M. haemofelis foi detectado por PCR em pacientes humanos no Brasil, portadores do vírus da AIDS, sugerindo potencial zoonótico. É sugerido o caráter emergente na população com o sistema imune comprometido e que mantém contato próximo com gatos na qual a infecção micoplásmica é latente (DUARTE et al., 1992; DOS SANTOS et al., 1998).

DNA de M. haemofelis foi detectado em pulgas de gatos (Ctenocephalides felis) podendo estar envolvido na transmissão (WOODS et al., 2005). Estudos adicionais tem documentado transmissão experimental pela administração intravenosa, intraperitonial e oral de sangue infectado, além da saliva e fezes (WILLI et at., 2007a) e em diferentes espécies de felinos selvagens (WILLI et at., 2007b).

Então, a despeito de maior conhecimento do potencial zoonótico de espécies de micoplasma, é fundamental o cuidado na manipulação de sangue e tecido de gatos infectados, principalmente entre médicos veterinários e 
SILVEIRA, E., PIMENTEL, M.C. e MARQUES, S.M.T. Mycoplasma haemofelis em gato, relato de caso. PUBVET, Londrina, V. 8, N. 13, Ed. 262, Art. 1741, Julho, 2014.

equipes auxiliares em hospitais e clínicas veterinárias. A micoplasmose é uma importante doença infecciosa no Brasil e o maior entendimento no impacto em animais de companhia, de produção e na fauna silvestre e o seu papel como agente zoonótico devem ser melhor investigados. Campanhas educativas para os grupos de risco são bem vindas e devem ser coordenadas por equipes de saúde para evitar a emergência desta doença.

\section{CONCLUSÃO}

O exame de PCR confirmou a suspeita clínica de micoplasmose felina. A terapêutica instituída reverteu o quadro clínico e houve êxito na cura clínica da paciente.

\section{REFERÊNCIAS}

ANDRÉ, M. R.; ADANiA, C. H.; ALlEgRetTI, S. M.; MACHADO, R. Z. Hemoplasmas in wild canids and felids in Brazil. Journal of Zoo and Wildlife Medicine 2011;42(2):342-347.

BIONDO, A. W.; DOS SANTOS, A. P.; GUIMARÃES, A. M.; VIEIRA, R. F.; VIDOTTO, O.; MACIEIRA D. B.; ALMOSNY, N. R.; MOLENTO, M. B.; TIMENETSKY, J.; DE MORAIS, H. A.; GONZÁLEZ, F. H.; MESSICK, J. B. A review of the occurrence of hemoplasmas (hemotrophic mycoplasmas) in Brazil. Revista Brasileira de Parasitologia Veterinária 2009; 18 (3): 1-7.

BRAGA, M. S.; ANDRÉ, M. R.; FRESCHI, C. R.; TEIXEIRA, M. C.; MACHADO, R. Z. Molecular detection of hemoplasma infection among cats from São Luís island, Maranhão, Brazil. Brazilian Journal of Microbiology 2012; 43 (2): 569-575.

DUARTE, M. I.; OLIVEIRA, M. S.; SHIKANAI-YASUDA, M. A.; MARIANO, O. N.; TAKAKURA, C. F.; PAGLIARI, C.; CORBETT, C. E. Haemobartonella-like microorganism infection in AIDS patients: ultrastructural pathology. Journal of Infectious Diseases 1992; 165(5): 976-7.

DOS SANTOS, A. P.; DOS SANTOS, R. P.; BIONDO, A.W.; DORA, J. M.; GOLDANI, L. Z,; DE OLIVEIRA, S. T.; GUIMARÃES, A. M. S.; TIMENETSKY, J.; DE MORAIS, H. A.; GONZÁLEZ, F. H. D.; MESSICK, J. B. Hemoplasma infection in an HIV positive patient, Brazil. Emerging Infectious Diseases 2008; 14(12): 1922-4.

NEIMARK, H.; JOHANSSON, K.E.; RIKIHISA, Y.; TULLY, J.G. Proposal to transfer some members of the genera Haemobartonella and Eperythrozoon to the genus Mycoplasma with descriptions of 'Candidatus Mycoplasma haemofelis', 'Candidatus Mycoplasma haemomuris', 'Candidatus Mycoplasma haemosuis' and 'Candidatus Mycoplasma wenyonii'. International Journal of Systematic and Evolutionary Microbiology 2001; 51:891-899.

NORSWORTHY, G. D. O paciente felino. 2. ed., Barueri: Manole, 2004. p. 299-302.

SYKES, J. E.; TERRY, J. C.; LINDSAY, L. L.; OWENS, S. D. Prevalences of various hemoplasma species among cats in the United States with possible hemoplasmosis. Journal of American Veterinary Medical Association 2008; 232(3): 372-379. 
SYKES, J. E. Feline Hemotropic Mycoplasmas. The Veterinary Clinics: Small Animal Practice 2010; 40: 1157-1170.

THRALL, M. A. Hematologia e Bioquímica Clínica Veterinária. São Paulo: Roca; 2007.

WILLI, B.; BORETTI, F. S.; MELI, M. L.; BERNASCONI, M .V.; CASATI, S.; HEGGLIN, D.; PUORGER, M.; NEIMARK, H.; CATTORI, V.; WENGI, N.; REUSCH, C. E.; LUTZ, H.; HOFMANNLEHMANN, R. Real-time PCR investigation of potential vectors, reservoirs, and shedding patterns of feline hemotropic mycoplasmas. Applied and Environmental Microbiolology 2007;73(12): 3798-3802.(a)

WILLI, B.; FILONI, C. ;CATÃO-DIAS, J. L.; CATTORI, V.; MELI, M. L. .; VARGAS, A.; MARTÍNEZ, F.; ROELKE, M. E.; RYSER-DEGIORGIS, M. P.; LEUTENEGGER, C. M.; LUTZ, H.; HOFMANNLEHMANN, R. Worldwide occurrence of feline hemoplasma infections in wild felid species. Journal of Clinical Microbiology 2007; 45(4):1159-1166.(b)

WOODS, J. E.; BREWER, M. M.; HAWLEY, J. R.; WISNEWSKI, N.; LAPPIN, M. R. Evaluation of experimental transmission of Candidatus Mycoplasma haemominutum and Mycoplasma haemofelis by Ctenocephalides felis to cats. American Journal of Veterinary Research 2005; 66(3): 1008-1012. 